\title{
DUKUNGAN ATASAN DAN TEMAN SEJAWAT MEMENGARUHI EKSPEKTASI PERAWAT DALAM PENERAPAN JENJANG KARIR
}

\author{
Tuti Afriani*, Rr. Tutik Sri Hariyati, Dewi Gayatri \\ Fakultas Ilmu Keperawatan Universitas Indonesia, Depok 16424, Indonesia \\ *E-mail: tuti.afriani@gmail.com
}

\begin{abstract}
Abstrak
Masalah utama yang dihadapi perawat di Indonesia adalah masalah kualitas sumber daya manusia. Sistem jenjang karir merupakan salah satu cara meningkatkan kualitas perawat dalam memberikan asuhan keperawatan. Penelitian ini bertujuan mengidentifikasi dukungan atasan dan teman sejawat ekspektasi perawat dalam penerapan jenjang karir di rumah sakit. Desain penelitian menggunakan korelasi deskriptif dengan pendekatan cross sectional. Jumlah sampel 145 perawat di salah satu rumah sakit Kabupaten Bogor Jawa Barat dengan teknik simple random sampling. Data dianalisis menggunakan uji Chi-Square dan regresi logistik berganda. Terdapat hubungan dukungan atasan $(\mathrm{p}=0,000)$ dan dukungan teman sejawat $(\mathrm{p}=0,023)$ dengan ekpektasi perawat terhadap penerapan jenjang karir di rumah sakit. Dukungan atasan $(\mathrm{OR}=3,806)$ dan jenis kelamin $(\mathrm{OR}=2,278)$ merupakan faktor yang paling dominan dengan ekspektasi perawat. Penelitian ini merekomendasikan agar pimpinan rumah sakit mendukung sistem jenjang karir dan memotivasi perawat meningkatkan kompetensi melalui sistem jenjang karir sehingga ekspektasi perawat meningkat terhadap manfaat dari sistem ini.
\end{abstract}

Kata kunci: dukungan atasan, dukungan teman sejawat, ekspektasi, jenjang karir perawat.

\section{Abstract}

Leader and Peer Support Influence Nurses' Expectations of The Career Ladder System Implementation. The main problem faced by nurses in Indonesia is a nursing quality. Nursing Clinical Ladder System (CLS) is one way to improve the quality of nurses in providing nursing care. This study is aimed to identify superiors and peers support affecting nurses' expectations towards the implementation of nursing clinical ladder system. This research is using Cross Sectional descriptive correlation and simple random sampling technique, and has involved 145 nurses at one hospital in Kabupaten Bogor Jawa Barat. Data were analyzed by Chi-Square test and multiple logistic regression. There is found a significant relationships between leader's support $(p=0.000)$ and colleagues' support $(p=0.023)$ and the nurses' expectations towards the implementation of CLS. The leader support $(O R=3.806)$ and the gender factor $(O R=2.278)$ are the dominant factors of nurses' expectation. It is recommended that hospital leaders support CLS and motivate nurses to improve their competence through this system so that CLP will increase the nurses' expectation to the benefits of CLS.

Keywords: superiors support, peers support, expectation, nursing clinical ladder system

\section{Pendahuluan}

Pelayanan kesehatan bermutu ditentukan oleh kualitas sumber daya manusia (SDM). Salah satu upaya meningkatkan mutu pelayanan adalah dengan adanya pengembangan staf melalui pengembangan karir perawat. Pengembangan karir perawat melalui jenjang karir terbukti dapat meningkatkan kepuasan kerja dan peningkatan kinerja perawat (Sitinjak, 2008).
Peningkatan kinerja dan kepuasan perawat juga berhubungan dengan persepsi dan harapan terhadap jenjang karir (Suroso, Hariyati, \& Pujasari, 2011; Mashudi, Hariyati, \& Allenidekania, 2013). Ekspektasi secara konseptual diartikan sebagai kepercayaan seseorang untuk berusaha mencapai hasil yang diinginkan.

Penelitian tentang ekspektasi perawat terhadap jenjang karir masih sangat sedikit. Salah satu- 
nya penelitan Han dan Kim (2014) yang meneliti perbedaan ekspektasi antara kepala ruangan (head nurses), charge nurses dengan perawat pelaksana meliputi unsur: finansial (gaji), kolaborasi, profesionalisme, manajemen, otonomi, dan penampilan kerja (work performance).

Rumah Sakit X di Kabupaten Bogor merupakan rumah sakit tipe B yang belum menerapkan sistem jenjang karir. Hasil wawancara dengan ketua komite keperawatan mengatakan sistem remunerasi belum berdasarkan penilaian kinerja yang adil, promosi dan pengangkatan tidak transparan yang tidak berdasarkan kemampuan perawat, kurangnya penghargaan kepada perawat yang berprestasi, kurangnya tantangan karena mengerjakan pekerjaan rutinitas. Pimpinan rumah sakit sudah berkomitmen untuk menerapkan sistem jenjang karir untuk meningkatkan kinerja dan performance perawat namun belum juga terlaksana.

Implementasi jenjang karir di rumah sakit tidak terlaksana tanpa ada dukungan dari organisasi dan manajer keperawatan. Nelson, Sasaman dan Philips (2008) menyatakan perawat mempunyai kesadaran dalam meningkatkan kompetensinya, sementara organisasi memberi fasilitas dan mendukung melalui kebijakan dalam pengembangan karir. Dill, Chuang, dan Morgan (2014) mengemukakan untuk mensukseskan jenjang karir, organisasi dapat bekerja sama dengan institusi pendidikan namun kemampuan memberi reward tergantung dari kekuatan dan dukungan pimpinan organisasi tersebut.

Jennings, Mutsch, dan Schleman (2009) mendapatkan bahwa perawat memutuskan untuk ikut dalam jenjang karir karena dorongan dan dukungan dari pimpinan $(99,1 \%)$, dukungan manajer $(69,9 \%)$, dan dukungan teman sejawat $(48,6 \%)$. Hal ini menunjukkan fenomena dukungan organisasi, atasan, dan teman sejawat perlu diidentifikasi agar dapat menjadi sumber informasi mengenai ekspektasi perawat dalam penerapan jenjang karir di rumah sakit.

\section{Metode}

Desain penelitian ini menggunakan deskriptif korelasi dengan rancangan penelitian crosssectional. Sampel diambil dengan teknik simple random sampling terhadap 145 perawat di ruang rawat inap, intalasi gawat darurat dan rawat jalan Rumah Sakit X Kabupaten Bogor. Data dikumpulkan dalam waktu tiga minggu dengan menggunakan kuesioner.

Kuesioner yang dibuat peneliti dengan mengajukan validitas konten kepada pembimbing. Kuesioner faktor pendukung mengacu kepada instrumen yang dimodifikasi dari Survey of Perceived Organization Support (Eisenberger, Huntington, Hutchison, \& Sowa, 1986). Kuesioner ekspektasi modifikasi dari Barnes Hibbert, Sigler, Fanning, dan Sandoval, (2011). Kuesioner menggunakan empat skala Likert. Validitas kuesioner diuji terhadap 30 orang perawat di rumah sakit berbeda, didapatkan nilai Alpha Cronbach 0,87 untuk kuesioner faktor pendukung dan 0,90 untuk kuesioner ekspektasi menggunakan SPSS analisis korelasi Pearson Product Moment. Penelitian ini telah melewati uji lolos etik dari komite etik Fakultas Ilmu Keperawatan Universitas Indonesia.

\section{Hasil}

Karakeristik Responden. Karakteristik responden mendapatkan hasil bahwa dari 145 responden terbanyak berusia antara 30-40 tahun (57,2\%), perempuan lebih banyak $104(69,3 \%)$, lama bekerja dibawah 9 tahun $(57,9 \%)$, pendidikan D3 Keperawatan (66,7\%), level hasil mapping terbanyak PK III $(39,3 \%)$, dan status kepegawaian PNS $(53,1 \%)$.

Hasil analisis Tabel 1 menunjukkan bahwa ekspektasi perawat terhadap jenjang karir di Rumah Sakit X masih rendah yaitu 52,4\%. Persentase ekspektasi perawat terhadap imbalan finansial $46,9 \%$, kolaborasi $21,4 \%$, pengembangan profesional $37,9 \%$, manajemen $29,7 \%$, otonomi $57,9 \%$ dan penampilan kerja $49 \%$. 
Hubungan Karakteristik dan Pengetahuan dengan Ekspektasi. Tabel 2 didapatkan hasil bahwa perawat yang berumur di atas 40 tahun mempunyai ekspektasi lebih tinggi terhadap jenjang karir daripada perawat yang berumur dibawahnya. Perawat yang bekerja lebih dari 9 tahun mempunyai ekspektasi lebih tinggi dibanding yang bekerja di bawah 9 tahun. Perempuan mempunyai ekspektasi lebih tinggi dan pendidikan D3 keperawatan mempunyai ekspektasi yang lebih tinggi terhadap jenjang karir, namun tidak ada hubungan bermakna antara karakteristik perawat dengan ekspektasi perawat terhadap penerapan jenjang karir di rumah sakit.

Tabel 2 menunjukkan perawat masing-masing penjenjangan hasil mapping mempunyai ekspektasi yang rendah terhadap penerapan jenjang karir. Perawat PK II mempunyai ekspektasi paling tinggi diantara perawat level lain. Tidak ada hubungan bermakna antara level jenjang karir dengan ekspektasi perawat di RS.

Ketua tim mempunyai ekspektasi lebih tinggi $(52,2 \%)$. Tidak ada hubungan antara posisi dalam pekerjaan dengan ekspektasi perawat terhadap penerapan jenjang karir. Perawat non PNS mempunyai ekspektasi yang tinggi terhadap penerapan jenjang karir daripada perawat PNS 51,5\%. Tidak ada hubungan bermakna antara status kepegawaian dengan ekspektasi terhadap jenjang karir. Tidak ada hubungan antara pengetahuan dengan ekspektasi.

Hubungan Faktor Pendukung dengan Ekspektasi. Hasil pada Tabel 3 adanya hubungan bermakna antara dukungan atasan dan teman sejawat dengan ekspektasi perawat terhadap jenjang karir $(p=0,000$ dan $p=0,023 ; \alpha=0,05)$.

Tabel 4 menunjukkan variabel yang paling berpengaruh terhadap ekspektasi perawat yaitu jenis kelamin dan dukungan atasan. Hasil analisis didapatkan wanita mempunyai ekspektasi yang lebih tinggi terhadap jenjang karir 2,278 kali dibanding laki-laki setelah dikontrol oleh dukungan atasan $(95 \% \mathrm{CI})$. Perawat yang mendapat dukungan atasan mempunyai ekspektasi 3,806 kali lebih tinggi setelah dikontrol oleh jenis kelamin.

Tabel 1. Ekspektasi Perawat

\begin{tabular}{|c|c|c|}
\hline Variabel & Frekuensi & Persentase (\%) \\
\hline \multicolumn{3}{|l|}{ Ekspekasi } \\
\hline Rendah & 76 & 52,4 \\
\hline Tinggi & 69 & 47,6 \\
\hline \multicolumn{3}{|l|}{ Imbalan Finansial } \\
\hline Rendah & 77 & 53,1 \\
\hline Tinggi & 68 & 46,9 \\
\hline \multicolumn{3}{|l|}{ Kolaborasi } \\
\hline Rendah & 114 & 78,6 \\
\hline Tinggi & 31 & 21,4 \\
\hline \multicolumn{3}{|l|}{ Pengembangan Profesional } \\
\hline Rendah & 90 & 62,1 \\
\hline Tinggi & 55 & 37,9 \\
\hline \multicolumn{3}{|l|}{ Manajemen } \\
\hline Rendah & 102 & 70,3 \\
\hline Tinggi & 43 & 29,7 \\
\hline \multicolumn{3}{|l|}{ Otonomi } \\
\hline Rendah & 61 & 42,1 \\
\hline Tinggi & 84 & 57,9 \\
\hline \multicolumn{3}{|l|}{ Penampilan Kerja } \\
\hline Rendah & 74 & 51,0 \\
\hline Tinggi & 71 & 49,0 \\
\hline
\end{tabular}


Tabel 2. Hubungan Karakteristik Perawat dengan Ekspektasi

\begin{tabular}{|c|c|c|c|c|c|c|c|}
\hline \multirow{3}{*}{ Variabel } & \multicolumn{4}{|c|}{ Ekspektasi } & \multirow{3}{*}{ Total } & \multirow{3}{*}{$\mathbf{p}$} & \multirow{3}{*}{ OR (CI 95\%) } \\
\hline & \multicolumn{2}{|c|}{ Rendah } & \multicolumn{2}{|c|}{ Tinggi } & & & \\
\hline & $\mathbf{n}$ & $\%$ & $\mathbf{n}$ & $\%$ & & & \\
\hline \multicolumn{8}{|l|}{ Umur } \\
\hline a. $<30$ tahun & 31 & 58,5 & 22 & 41,5 & 53 & \multirow[t]{3}{*}{0,130} & 1,331 \\
\hline b. $30-40$ tahun & 43 & 51,6 & 40 & 48,4 & 83 & & $(0,7 ; 2,6)$ \\
\hline c. $>40$ tahun & 2 & 22,2 & 7 & 77,8 & 9 & & $\begin{array}{c}4,932 \\
(0,9 ; 26,0)\end{array}$ \\
\hline \multicolumn{8}{|l|}{ Lama Kerja } \\
\hline a. $<9$ Tahun & 41 & 53,2 & 36 & 46,8 & 77 & \multirow[t]{2}{*}{0,831} & 1,074 \\
\hline b. > 9 Tahun & 53 & 51,5 & 33 & 48,5 & 68 & & $(0,5 ; 2,1)$ \\
\hline \multicolumn{8}{|l|}{ Jenis Kelamin } \\
\hline a. Laki-laki & 26 & 63,4 & 15 & 36,6 & 41 & \multirow{2}{*}{0,096} & 1,872 \\
\hline b. Perempuan & 50 & 48,1 & 54 & 51,9 & 104 & & $(0,8 ; 3,9)$ \\
\hline \multicolumn{8}{|l|}{ Tingkat Pendidikan } \\
\hline a. D3 Keperawatan & 49 & 49,0 & 51 & 51,0 & 100 & \multirow{2}{*}{0,220} & 0,641 \\
\hline b. S1 Keperawatan/Ners & 27 & 60,0 & 18 & 40,0 & 45 & & $(0,3 ; 1,3)$ \\
\hline \multicolumn{8}{|c|}{ Penjenjangan Hasil Mapping } \\
\hline a. PK 0 & 11 & 61,1 & 7 & 38,9 & 18 & \multirow[t]{5}{*}{0,747} & 1,323 \\
\hline b. PK I & 19 & 54,3 & 16 & 45,7 & 35 & & $(0,4 ; 4,2)$ \\
\hline c. PK II & 16 & 45,7 & 19 & 54,3 & 35 & & 1,866 \\
\hline d. PK III & 30 & 52,6 & 27 & 47,4 & 57 & & $(0,6 ; 5,9)$ \\
\hline & & & & & & & $\begin{array}{c}1,414 \\
(0,5 ; 4,2)\end{array}$ \\
\hline \multicolumn{8}{|l|}{ Posisi Dalam Pekerjaan } \\
\hline a. Ketua Tim & 11 & 47,8 & 12 & 52,2 & 23 & \multirow{2}{*}{0,631} & 0,806 \\
\hline b. Perawat Pelaksana & 65 & 53,3 & 57 & 46,7 & 122 & & $(0,3 ; 1,9)$ \\
\hline \multicolumn{8}{|l|}{ Status Kepegawaian } \\
\hline a. PNS & 43 & 55,8 & 34 & 42,2 & 77 & \multirow{2}{*}{0,379} & 1,341 \\
\hline b. Non PNS & 33 & 48,5 & 35 & 51,5 & 68 & & $(0,7 ; 2,9)$ \\
\hline \multicolumn{8}{|l|}{ Pengetahuan tentang JK } \\
\hline a. Rendah & 47 & 56,5 & 36 & 43,4 & 83 & \multirow[t]{2}{*}{0,240} & 1,486 \\
\hline b. Tinggi & 29 & 46,8 & 33 & 53,2 & 62 & & $(0,8 ; 2,9)$ \\
\hline
\end{tabular}

\section{Pembahasan}

Penelitian ini ditemukan bahwa perawat yang berumur 40 tahun kebawah mempunyai ekspektasi yang rendah terhadap penerapan jenjang karir, berbeda dengan teori yang menyatakan bahwa umur produktif semangat dalam mencari pengetahuan melalui pelatihan dan pengembangan diri. Suroso, et al. (2011) juga menyatakan tidak ada hubungan bermakna antara umur, jenis kelamin, pendidikan, lama kerja dan level jenjang karir dengan kinerja,
Robbins dan Judge (2013) menyatakan adanya hubungan positif antara senioritas dengan produktivitas pekerjaan. Semakin lama bekerja semakin kecil kemungkinan pengunduran diri. Perawat yang umur di atas 40 lebih produktif dan mempunyai harapan terhadap pekerjaan hal ini karena kebutuhan dasar sudah terpenuhi dan lebih mencari upaya untuk pencapaian harga diri dan kebebasan melalui jenjang karir.

Perempuan mempunyai ekspektasi lebih tinggi daripada laki-laki. Hal ini karena perempuan 
cenderung lebih telaten dan sabar dalam menjalani proses jenjang karir dibanding laki-laki dalam melakukan proses pada tiap tahap penerapan jenjang karir.

Hasil penelitian mendapatkan tidak ada hubungan bermakna antara tingkat pendidikan dengan tinggi rendahnya ekspektasi perawat terhadap penerapan jenjang karir. Mangkunegara (2009) bahwa individu dengan pendidikan tinggi mampu berpikir kritis, luas dan memiliki inisiatif serta kreatifitas yang tinggi sehingga dapat menemukan solusi atas permasalahan yang ada. Penelitian Hasanuddin dan Kadir (2013) menyatakan ada hubungan antara faktor pendidikan dan pelatihan dengan upaya pengembangan karir.

Bila dihubungkan antara lama kerja dengan tingkat pendidikan didapatkan bahwa sebagian besar perawat Ners bekerja masih dibawah 10 tahun artinya perawat tersebut masih menempati posisi perawat pelaksana. Sosialisasi jen- jang karir belum menyeluruh kepada semua perawat terutama kepada perawat pelaksana sehingga perlu adanya sosialisasi kepada semua perawat untuk meningkatkan ekspektasi perawat terhadap sistem jenjang karir. Hal ini masih kurangnya pengajaran tentang jenjang karir yang didapatkan pada institusi pendidikan, perawat lebih banyak mendapatkan pengetahuan tentang jenjang karir secara detil dari workshop dan pelatihan.

Ekspektasi paling rendah mayoritas perawat dari penelitian ini adalah perawat PK 0 yaitu perawat yang bekerja di atas 1 tahun dan sudah menyelesaikan masa orientasi, namun belum kenaikan jenjang untuk ditempatkan pada jenjang PK I. Penelitian yang dilakukan oleh Ari dan Insook (2013) menyatakan bahwa perawat spesialis 2 (Expert) memiliki persepsi yang lebih baik terhadap jenjang karir daripada perawat spesialis 1 (Competent/Proficient), perawat generalis (Novice/Advance Beginner), dan perawat baru (New Nurse).

Tabel 3. Hubungan Faktor Pendukung dengan Ekspektasi

\begin{tabular}{|c|c|c|c|c|}
\hline \multirow{3}{*}{ Variabel } & \multicolumn{2}{|c|}{ Ekspektasi } & \multirow{3}{*}{$X^{2}$} & \multirow{3}{*}{$\mathbf{p}$} \\
\hline & Rendah & Tinggi & & \\
\hline & $\mathrm{N}(\%)$ & $\mathbf{N}(\%)$ & & \\
\hline \multicolumn{5}{|l|}{ Faktor Pendukung } \\
\hline Dukungan RS & & & 2,316 & 0,088 \\
\hline Kurang & $47(58,0)$ & $34(42,0)$ & & \\
\hline Baik & $29(45,3)$ & $35(54,7)$ & & \\
\hline Dukungan Atasan & & & 12,347 & $0,000 *$ \\
\hline Kurang & $56(64,4)$ & $31(35,6)$ & & \\
\hline Baik & $20(34,5)$ & $38(65,5)$ & & \\
\hline Dukungan Teman & & & 4,701 & $0,023 *$ \\
\hline Kurang & $54(59,3)$ & $37(40,7)$ & & \\
\hline Baik & $22(40,7)$ & $32(59,3)$ & & \\
\hline
\end{tabular}

Keterangan: ${ }^{*} \alpha=0,05$

Tabel 4. Pemodelan Akhir Variabel yang Berhubungan dengan Ekspektasi Perawat

\begin{tabular}{lcccc}
\hline \multicolumn{1}{c}{ Variabel } & B & SE & p & OR \\
\hline Jenis Kelamin & 0,824 & 0,406 & 0,043 & 2,278 \\
Dukungan Atasan & 1,337 & 0,368 & 0,000 & 3,806 \\
Constant & $-3,388$ & 0,965 & & \\
\hline
\end{tabular}


Posisi dalam pekerjaan mendapatkan hasil bahwa ketua tim memiliki ekspektasi terhadap penerapan jenjang karir lebih tinggi dari perawat pelaksana Penelitian Han dan Kim (2014) menyatakan bahwa ekspektasi paling tinggi adalah pada ketua tim, dimana ekspektasi terhadap jenjang karir yang terdiri dari ekspektasi terhadap imbalan, profesionalisme, penampilan kerja, dan otonomi.

Perawat PNS memiliki ekspektasi yang lebih rendah dibandingkan perawat non PNS. Menurut Gatot dan Adisasmito (2005) karyawan PNS lebih memiliki ketenangan dengan statusnya, perawat PNS mengerti peluang pengembangan karir dan cukup tenang dengan jaminan hari tuanya. Sebaliknya hal ini tidak dialami oleh pegawai yang berstatus non PNS. Sistem pengembangan karir dalam konteks sistem penghargaan perawat sudah dikembangkan untuk Pegawai Negeri Sipil (PNS) yang tertuang dalam SK Menpan No.94/Kep/M.PAN $/ 11 / 2001$ tentang jabatan fungsional perawat termasuk angka kreditnya, namun bagi tenaga Non PNS tidak ada aturan mengenai kenaikan pangkat atau jabatan.

Menurut peneliti dengan adanya program jenjang karir perawat non PNS memiliki peluang untuk naik jabatan tanpa melihat status kepegawaian. Perawat dengan dedikasi dan kineja yang baik melalui jenjang karir akan mendapat promosi untuk menjadi ketua tim atau kepala ruangan. Ekspektasi perawat non PNS terhadap jenjang karir meningkat dengan alasan tersebut diatas.

Nelson dan Cook (2008) menyatakan bahwa motivasi untuk mengikuti jenjang karir berhubungan dengan pengetahuan tentang jenjang karir dan persepsi partisipan terhadap jenjang karir. Penelitian ini menemukan bahwa tidak ada hubungan antara pengetahuan dengan ekspekasi perawat terhadap penerapan jenjang karir hal ini disebabkan sosialisasi jenjang karir di RS X di Kabupaten Bogor baru berjalan sebagian, belum seluruh perawat terpapar dengan sistem jenjang karir.
Rendahnya pengetahuan perawat menjadi hambatan untuk mengikuti program jenjang karir. Carryer, Russell, dan Budge (2007) menekankan perlunya peningkatan pengetahuan dan memberikan pendidikan tentang sistem jenjang karir, sehingga perawat cenderung mengembangkan perilaku yang positif bila perawat lebih tahu tentang program ini

Donley dan Flaherty (2008) menyampaikan bahwa untuk mencapai keberhasilan program jenjang karir perlu adanya sistem pendukung yang membantu perawat memahami jenjang karir ini. Sistem pendukung yang disediakan baik melalui pelatihan, kedekatan perawat mentor melalui konsultasi personal dan melalui perbaikan sistem jenjang karir secara terus menerus.

Burket, Felmlee, Greider, Hippensteel, Rohrer, dan Shay (2010) dalam penelitian menemukan keberhasilan jenjang karir tergantung dari banyak faktor terdiri dari dukungan dari pimpinan keperawatan, dukungan manejer keperawatan, antusias staff perawat dan dedikasi dari anggota komite. Program jenjang karir dapat bertahan kuncinya adalah mengikuti siklus pembelajaran yaitu mengidentifikasi tujuan, perubahan rencana, melakukan aksi dan proses evaluasi.

Hasil penelitian menunjukkan masih rendahnya dukungan terhadap penerapan jenjang karir di rumah sakit. Hal ini bisa dipahami karena rumah sakit baru memulai pelaksanaan jenjang karir pada tahun 2014 lalu.

Menurut peneliti, hasil penelitian yang didapatkan sesuai dengan kondisi riil dilapangan. Organisasi rumah sakit belum terlihat komitmen dan upaya dalam penerapan jenjang karir. Tim jenjang karir yang sudah dibentuk belum melakukan kegiatan untuk memulai penerapan jenjang karir. Kurangnya koordinasi dan kolaborasi antara pimpinan, bidang keperawatan dan komite keperawatan dengan tim jenjang karir juga menjadi hambatan. Prinsip pengembangan karir perawat menyatakan perlu adanya 
komitmen yang tinggi dari pimpinan untuk pengembangan karir perawat (Depkes, 2008).

Dukungan atasan dan dukungan teman sejawat dinilai cukup baik dalam meningkatkan ekspektasi perawat terhadap penerapan jenjang karir. Penelitian mengindikasikan bahwa dukungan atasan lebih berpengaruh dibandingkan dukungan organisasi (Eisenberger, et al., 1986). Penelitian Kopp dan Stachowski (2013) juga menemukan dukungan atasan lebih berpengaruh dibanding dukungan dari teman sejawat.

Ekspektasi perawat terhadap penerapan jenjang karir masih rendah yaitu $52,2 \%$. Menurut peneliti kurangnya ekspektasi perawat terhadap penerapan jenjang karir disebabkan belum adanya tindak lanjut dan tindakan konkrit dari manajemen rumah sakit untuk mewujudkan program jenjang karir ini. Pelaksanaan pemetaan yang sudah dilakukan belum secara resmi mendapat pengakuan dari pimpinan rumah sakit sehingga belum terlihat dampaknya baik secara fisik berupa perbedaan remunerasi tiap level maupun secara non fisik misalnya semangat untuk meningkatkan karir melalui pendidikan yang berkelanjutan. Pembentukan tim jenjang karir juga sudah dibuat namun sampai saat ini belum ada karya nyata dari tim jenjang karir tersebut.

Penelitian ini menemukan bahwa ekpektasi perawat dari persentase tertinggi ke yang rendah meliputi ekspektasi terhadap otonomi, penampilan kerja, imbalan finansial, manajemen, pengembangan profesional dan kolaborasi. Berbeda dengan penelitian yang dilakukan oleh Han dan Kim (2014) yang menyatakan ekspektasi perawat tertinggi terhadap kolaborasi, imbalan finansial, pengembangan profesional, penampilan kerja, otonomi, dan manajemen.

Penelitian ekspektasi perawat paling tinggi terhadap otonomi. Perawat mempunyai persepsi dengan adanya sistem jenjang karir meningkatkan kemandirian terhadap asuhan keperawatan yang diberikan. Perawat juga dapat memutuskan sendiri terhadap asuhan yang diberikan berdasarkan kompetensi perawat. Perawat berasumsi dengan adanya jenjang karir dapat diberi kewenangan dan otoritas dalam bertindak sesuai dengan level jenjang karir perawat.

Jenjang karir memberikan ukuran yang objektif untuk mencapai otonomi dan pertumbuhan profesional (Buchan, 1999; Cote \& Burwell, 2007; Jennings, et al., 2009). Penelitian di atas juga menyampaikan bahwa sistem jenjang karir memberikan dampak yang positif tidak hanya pertumbuhan profesional namun juga otonomi dalam praktik keperawatan dan memberikan kepuasan dalam bekerja

Komponen kedua hasil penelitian ini adalah ekspektasi perawat terhadap penerapan jenjang karir yaitu penampilan kerja. Penampilan kerja (work performance) adalah pencapaian kualitas dan kuantitas seorang perawat dalam melaksanakan tugas sesuai tanggung jawab (Hariyati, 2014). Perawat mempunyai persepsi bahwa penilaian kinerja penting untuk menempatkan perawat sesuai dengan level jenjang karir dan pemberian remunerasi berbasis kinerja.

Komponen ketiga ekspektasi perawat terhadap imbalan finansial. Robbin dan Judge (2013) menyatakan bahwa uang dapat memotivasi seseorang dalam bekerja. Agar uang dapat memotivasi Pekerja harus memenuhi beberapa kondisi sebagaimana disampaikan teori Vroom (1995) tentang teori ekspektasi yang terdiri dari tiga elemen yaitu, pertama expectancy yaitu kepercayaan seseorang bahwa sesuatu yang didapat sesuai dengan keinginan atau harapannya, dalam hal ini perawat masih menganggap balasan finansial merupakan hal yang penting dan diinginkan saat ini. Kedua instrumentality uang dipersepsikan sebagai ganjaran dari apa yang sudah dilakukan, perawat menganggap bahwa insentif yang didapatkan tidak sesuai dengan beban kerja yang diberikan. Ketiga Valence, apakah nilai reward cukup bernilai bagi individu.

Pada prinsipnya pemberian remunerasi harus memenuhi prinsip keadilan dan memenuhi 
kejelasan atau keterbukaan. Bila remunerasi sesuai dengan kebutuhan dan harapan perawat, maka remunerasi tersebut dapat meningkatkan minat dan motivasi dalam bekerja.

Komponen keempat dari ekspektasi perawat terhadap jenjang karir dalam penelitian ini adalah pengembangan profesional. Menurut Cooper (2009) pengembangan profesional adalah komitmen secara konstan untuk memelihara level kemampuan perawat melalui jalur karir.

Pengembangan profesional melalui jalur formal misalnya perawat D3 atau perawat vokasi melanjutkan pendidikan ke jenjang yang lebih tinggi S1 dan S2 keperawatan atau perawat profesional. Pelatihan baik inhouse training maupun pelatihan diluar juga diatur oleh diklat rumah sakit sehingga setiap perawat mempunyai hak yang sama untuk mendapatkan pelatihan secara bergiliran. Informasi-informasi tentang jenjang karir baik tersedia di masingmasing ruangan sehingga setiap perawat terpapar dengan jenjang karir ini. Kepala ruangan beserta ketua tim hendaknya mengetahui kebutuhan masing-masing staf untuk peningkatan karir mereka sehingga setiap perawat mendapat kesempatan untuk mengikuti pelatihan baik yang diadakan didalam maupun diluar rumah sakit.

Komponen kelima ekspektasi perawat terhadap penerapan jenjang karir dari hasil penelitian ini adalah manajemen. Penelitian Bjork, Hansen, Samdal, Torstad, dan Hamilton (2007) menemukan perawat dalam penelitian tersebut kurang dorongan dan kedekatan antara peserta jenjang karir dengan pimpinan keperawatan mengakibatkan rendahnya angka untuk berpartisipasi dalam sistem jenjang karir. Penelitian juga memperlihatkan pentingnya peran manajer sebagai pendukung dan fasilitator dalam pengembangan profesional perawat (Reay, GoldenBiddle, \& Germann, 2003).

Komponen keenam ekspektasi perawat terhadap penerapan jenjang karir yang ditemukan pada penelitian ini adalah kolaborasi. Keber- hasilan dan keberlangsungan sistem jenjang karir tergantung dari banyak faktor, yaitu dukungan dari pimpinan keperawatan, antusias staf, dan dedikasi dari anggota komite keperawatan serta komite jenjang karir. Anggotaanggota yang terdiri dari perawat manajer, perawat pendidik, perawat ahli dan staf perawat perlu berkolaborasi agar sistem ini terlaksana. (Burket, et al, 2010).

\section{Kesimpulan}

Penelitian ini menemukan bahwa tidak ada hubungan antara karakteristik individu yang meliputi umur, jenis kelamin, lama kerja, pendidikan, posisi dalam pekerjaan, penjenjangan hasil pemetaan dan status kepegawaian dengan ekspektasi terhadap penerapan jenjang karir.

Ekspektasi perawat dalam penerapan jenjang karir paling tinggi adalah ekspektasi terhadap otonomi diikuti oleh ekspektasi terhadap penampilan kerja, imbalan finansial, pengembangan profesional, manajemen, dan paling rendah ekspektasi terhadap kolaborasi.

Dukungan atasan dan dukungan teman sejawat mempunyai hubungan yang bermakna dengan ekspektasi perawat. Ekspektasi perawat terhadap penerapan jenjang karir di Rumah Sakit $\mathrm{X}$ Kabupaten Bogor umumnya masih kurang baik. Pengetahuan perawat terhadap jenjang karir tergolong kategori sedang, namun tidak ada hubungan bermakna antara pengetahuan dengan ekspektasi perawat terhadap penerapan jenjang karir di rumah sakit.

Faktor determinan yang paling berpengaruh terhadap ekspektasi terhadap implementasi jenjang karir adalah dukungan atasan dan jenis kelamin. Semakin besar dukungan atasan akan meningkatkan ekspektasi perawat sebanyak tiga kali dibandingkan perawat yang kurang mendapat dukungan atasan.

Keberhasilan program jenjang karir perlu adanya komitmen yang kuat dari pimpinan untuk melakukan langkah-langkah penerapan jenjang 
karir. Pimpinan rumah sakit lebih dahulu mengesahkan penerapan sistem jenjang karir, melakukan pemetaan perawat, membuat daftar kompetensi tiap level jenjang karir, dan melakukan sosialisasi kepada seluruh perawat di rumah sakit. Koordinasi tim jenjang karir dengan komite keperawatan dan pimpinan rumah sakit juga perlu dilakukan secara intensif. Apabila diperlukan rumah sakit dapat melakukan studi banding membuat kesepakatan dengan institusi pendidikan atau rumah sakit lain sebagai mitra bestari dalam pelaksanaan program jenjang karir di rumah sakit (MS, MK, TN).

\section{Referensi}

Ari, M., \& Insook, K. (2013). Relationship of perception of clinical ladder system with professional self concept and empowerment based of nurses' clinical career stage. Journal of Korea Academy of Nursing Administration, 19 (3), 254-264.

Barnes, K.L., Hibbert, M., Sigler, K., Fanning, L., \& Sandoval, L. (2011). Clinical ladder program participants and job satisfaction: $A$ comparison (Disertasi Doktor, Southern Nazarene University Oklahama). Diperoleh dari ProQues Dissertation and Theses. (UMI No 1502046).

Bjork, I.T., Hansen, B.S., Samdal, G.B., Torstad, S., \& Hamilton, G. A. (2007). Evaluation of clinical ladder participation in Norway. Journal of Nursing Scholarship: First Quarter, 39 (1), 88-89.

Buchan J. (1999). Evaluating the benefits of a clinical ladder for nursing staff: An International review. International Journal Nursing Study, 36 (2), 137-144.

Burket, T.L., Felmlee, M., Greider, P., Hippensteel, D.M., Rohrer, E.A., \& Shay, M.L. (2010). Clinical ladder program evolution: Journey from novice to expert to enhacing outcomes. The Journal of Continuing Education in Nursing, 41 (8), 369-374.
Carryer, J., Russell, A., \& Budge, C. (2007). Nurses' understandings of the Professional Development Recognition Programme. Nursing praxis in New Zealand Inc, 23 (2), 5-13. (PMID: 18293653).

Cooper, E. (2009). Creating a culture of professional development: A milestone pathway tool for registered nurses. The Journal of Continuing Education in Nursing, 40 (11), 501-508.

Cote, D.A., \& Burwell, K.T. (2007). A revised nephrology nurses' clinical ladder. Nephrology Nursing Journal, 34 (2), 243.

Depkes RI. (2008). Pengembangan dan pemberdayaan SDM Kesehatan. Jakarta: Depkes RI. Diperoleh dari http://www.depkes.go.id/

Dill, J.S., Chuang, E., \& Morgan, J.C. (2014). Healthcare organization-education partnerships and career ladder programs for health care workers. Social Science \& Medicine, 122, 63-71. doi: 10.1016/j.socscimed.2014. 10.021 .

Donley, R., \& Flaherty, M.J. (2008). Promoting professional development: Three phases of articulation in nursing education and practice. OJIN: The Online Journal of Issues in Nursing, 13 (3), 2-8.

Eisenberger, R., Huntington, R., Hutchison, S., \& Sowa, D. (1986). Perceived organizational support. Journal of Applied Psychology, 71, 500-507.

Gatot, D.B., \& Adisasmito, W. (2005). Hubungan karakteristik perawat, isi pekerjaan dan Lingkungan pekerjaan terhadap kepuasan kerja perawat di Instalasai Rawat Inap RSUD Gunung Jati Cirebon. Jurnal Makara Seri Kesehatan, 9 (6), 1-8.

Han, Y., \& Kim, K. (2014). A survey on Registered Nurses' expectation of the clinical ladder program in small to medium sized hospitals. Advanced Science and Technology Letters (Healthcare an Nursing 2014), 61 (1), 66-69. doi: 10.14257/astl.2014.61.16. 
Hariyati, R.T.S. (2014). Perencanaan, pengembangan dan utilisasi tenaga keperawatan. Jakarta: Rajawali Press.

Hasanuddin, A., \& Kadir, A. (2013). Faktor-faktor yang berhubungan dengan upaya pengembangan karir perawat di rumah sakit Bhayangkara Mappa Oudang Makassar. Jurnal Ilmiah Kesehatan Diagnosis, 2 (1), 18. ISSN: 2302-1721.

Kopp, L.R., \& Stachowski, A. (2013). The effect of perceived supervisor support on employee work life balance, job satisfaction, organizational commitment, and organizational citizenship behavior (Unpublished, Master theses). University of Wincostin-Stout, Menomonie.

Jennings, K., Mutsch, K.S., \& Schleman, J. (2009). Factors contributing to decision to participate or not participate in a clinal ladder program. ProQuest Dissertations. Northern Kentucky University. UMI Number: 1462240.

Mangkunegara, P.A.A. (2009). Manajemen sumber daya manusia (Cetakan kesembilan). Bandung: Remaja Rodakarya.

Mashudi, D., Hariyati, R.T.S., \& Allenidekania (2013). Pengaruh penerapan jenjang karir perawat klinik terhadap kinerja dan kepuasan kerja perawat pelaksana di instalasi rawat inap B RSUP Fatmawati (Tesis, Tidak dipublikasikan). Fakultas Ilmu Keperawatan Universitas Indonesia, Jakarta.
Nelson, M. J., \& Cook, P.F (2008). Evaluation of career ladder program in a ambulatory care environment. Nursing economic, 26 (11), 353-360.

Nelson, J., Sassaman, B., \& Phillips, A. (2008). Career ladder program for registered nurses in ambulatory care. Nursing economic, 26 (6), 393-398.

Reay, T., Golden-Biddle, K., \& Germann, K. (2003). Challenges and leadership strategies for managers of nurse practitioners. Journal of nursing management, 11 (6), 396-403.

Robbins, S.P. \& Judge, T.A. (2013). Organization behavior (15th Ed.). USA: Prentice Hall.

Sitinjak, L. (2008). Pengaruh penerapan sistem jenjang karier terhadap kepuasan kerja perawat di RS PGI Â Cikini (Tesis, Tidak dipublikasikan). Fakultas Ilmu Keperawatan Universitas Indonesia, Jakarta.

Suroso, J., Hariyati, R.T.S., \& Pujasari, H. (2011). Hubungan persepsi tentang jenjang karir dengan kepuasan kerja dan kinerja perawat RSUD Banyumas (Tesis, tidak dipublikasikan). Fakultas Ilmu Keperawatan Universitas Indonesia, Jakarta.

Vroom, V.H. (1995). Work and motivation (pp. 1727). San Francisco, CA: Jossey-Bass. 